\title{
Positive Antinuclear Antibody Test
}

National Cancer Institute

\section{Source}

National Cancer Institute. Positive Antinuclear Antibody Test. NCI Thesaurus. Code C50701.

Indicates that antibodies directed against nuclear antigens have been detected. 